\title{
LETTER
}

\section{Measurement of monocyte apoptosis, plasma IL-1 $\beta$ and PR3 activity as an approach to evaluate the immunological status in sepsis}

\author{
Hong-Ping Qu*, Zhao-Jun Liu and Jia-Lin Liu \\ See related research by Giamarellos-Bourboulis et al., http://ccforum.com/content/15/1/R27
}

In a previous issue of Critical Care, GiamarellosBourboulis and colleagues published an article in which they drew a conclusion that inhibition of caspase- 1 and defective IL- $1 \beta$ production is an important immunological feature in sepsis [1]. Based on the knowledge of previous research, we would like to make some remarks.

Firstly, peripheral blood mononuclear cells (PBMC) mainly consist of monocytes, T cells, B cells and natural killer cells, of which only monocytes are the high producer of IL-1 $\beta$ and TNF $\alpha$. The proportion of monocytes in PBMC may therefore greatly affect production of these cytokines. In earlier research, Giamarellos-Bourboulis and colleagues demonstrated that the percentage of monocyte apoptosis was over $50 \%$ in about half of their septic subjects [2]. In their recent study, however, these authors found that downregulation of IL-1 $\beta$ followed a different pattern to TNF $\alpha$; release of TNF $\alpha$ was not impaired after lipopolysaccharide stimulation of PBMC of patients with uncomplicated sepsis and with severe sepsis [1], suggesting that the monocytes of these subjects did not undergo apoptosis. The introduction of methods to check the apoptosis of monocytes and their proportion in PBMC is thus quite necessary.

Secondly, the authors concluded that defective IL-1 $\beta$ production is an important immunological feature in sepsis. According to Fahy and colleagues' research, however, the plasma IL-1 $\beta$ level was significantly elevated in patients with septic shock in comparison with normal control subjects [3]. A possible explanation for this difference is that caspase- 1 is not the unique enzyme that can activate IL-1 $\beta$. Recent studies suggest that neutrophils are the major source for processing IL-1 $\beta$ via PR3 during acute inflammatory conditions [4]. To reveal the real immunological status in sepsis, therefore, it would be better in future research to measure the plasma IL-1 $\beta$ level and the activity of PR3 in neutrophils in septic patients simultaneously, in addition to ex vivo experiments.

\section{Abbreviations \\ IL, interleukin; PBMC, peripheral blood mononuclear cells; TNF, tumor necrosis factor.}

\section{Competing interests}

The authors declare that they have no competing interests.

Published: 28 June 2011

\section{References}

1. Giamarellos-Bourboulis EJ, van de Veerdonk FL, Mouktaroudi M, Raftogiannis M, Antonopoulou A, Joosten LA, Pickkers P, Savva A, Georgitsi M, van der Meer JW, Netea MG: Inhibition of caspase-1 activation in gram-negative sepsis and experimental endotoxemia. Crit Care 2011, 15:R27.

2. Giamarellos-Bourboulis EJ, Routsi C, Plachouras D, Markaki V, Raftogiannis M, Zervakis D, Koussoulas V, Orfanos S, Kotanidou A, Armaganidis A, Roussos C, Giamarellou H: Early apoptosis of blood monocytes in the septic host: is it a mechanism of protection in the event of septic shock? Crit Care 2006, 10:R76.

3. Fahy RJ, Exline MC, Gavrilin MA, Bhatt NY, Besecker BY, Sarkar A, Hollyfield JL, Duncan MD, Nagaraja HN, Knatz NL, Hall M, Wewers MD: Inflammasome mRNA expression in human monocytes during early septic shock. Am J Respir Crit Care Med 2008, 177:983-988.

4. van de Veerdonk FL, Netea MG, Dinarello CA, Joosten LA: Inflammasome activation and IL-1 $\beta$ and IL-18 processing during infection. Trends Immunol 2011, 32:110-116.

doi:10.1186/cc10248

Cite this article as: Qu H-P, et al: Measurement of monocyte apoptosis, plasma IL-1 $\beta$ and PR3 activity as an approach to evaluate the immunological status in sepsis. Critical Care 2011, 15:434.

\footnotetext{
*Correspondence: hongpingqu@yahoo.com.cn

Department of Critical Care Medicine and Respiratory Intensive Care Unit, Ruilin Hospital, Shanghai Jiao Tong University School of Medicine, No. 197 The Second RuiJin Road, 200025 Shanghai, China
} 